\title{
Leptomeningeal gliomatosis
}

\author{
Bryan Ashworth, Alexander Gordon
}

\begin{abstract}
The diagnosis of leptomeningeal gliomatosis is discussed in relation to a single case studied in detail. Histology showed extensive subarachnoid spread of tumour that seemed to originate in an astrocytoma of the ventricular wall. The spinal fluid was xanthochromic with a high protein content. Reports of primary leptomeningeal gliomatosis are reviewed and the need for detailed histological study of the brain in such cases is emphasised.
\end{abstract}

$(F$ Neurol Neurosurg Psychiatry 1994;57:471-473)

Cases are on record in which a glioma, usually an astrocytoma, seems to have arisen in the leptomeninges of the brain or spinal cord. If neural tissue is involved at all it is by invasion. In the case reported here a widespread subarachnoid tumour was found with no overt primary lesion of the parenchyma. It was only when the lining of the ventricular system was examined microscopically that an intrinsic tumour, invisible to the naked eye, was found in relation to the wall of the right lateral ventricle. Clinical diagnosis in such cases is difficult and important considerations are discussed.

\section{Case study}

A previously vigorous independent woman aged 69 was admitted to hospital after being found naked in a cold bedroom. She was alert and well nourished but disorientated, agitated, and frightened. She gave a history of poor appetite, weight loss, and general malaise.

Clinical neurological examination was negative. Her temperature was $36 \cdot 2^{\circ} \mathrm{C}$ and there were no features of meningeal irritation. Her spinal fluid was xanthochromic with a protein concentration of $13.2 \mathrm{~g} / 1$ (normal range $0.2-0.6 \mathrm{~g} / \mathrm{l})$, a glucose concentration of 4.9 $\mathrm{mmol} / 1$ (normal range $2.3-4.5 \mathrm{mmol} / \mathrm{l}$ ), and a lymphocytosis of $30 \mathrm{cells} / \mathrm{mm}^{3}$. An EEG showed a widespread diffuse $\delta$ rhythm at $2 \mathrm{~Hz}$. A CT scan of the head showed only minor atrophic changes.

She remained confused but apyrexial. Over the next few weeks a profound memory defect with confabulation developed. Spinal fluid analysis remained essentially unchanged and repeat of the CT scan showed only slight dilatation of the lateral ventricles. Bilateral carotid arteriograms showed minor atheromatous changes without occlusion of any of the main vessels; no cerebral displacement was seen. After six weeks she was more agitated, with urinary incontinence, and her blood pressure was unstable. During the next month she lapsed into coma and developed a left lateral rectus palsy. The working clinical diagnosis throughout had been encephalitis.

\section{NECROPSY}

The scalp, skull, dura, and venous sinuses were normal. The leptomeninges of brain and cord showed extensive diffuse and nodular thickening by a semitranslucent tumour. Apart from a purulent tracheobronchitis no significant abnormality was found outside the nervous system.

The leptomeninges were generally thickened and semitranslucent over the entire surface of the brain, particularly the ventral surface of the stem where the cranial nerves were obscured and the right third nerve was infiltrated and distended by tumour. Both internal carotid arteries were cuffed by tumour. No significant herniation was found.

Serial coronal sections of the cerebral hemispheres showed no overt tumour and an essentially normal ventricular system without evidence of displacement. Tumour was present in the cisterna ambiens surrounding the internal cerebral veins and pineal gland, which did not, however, seem to be implicated. Section of the brain stem and cerebellum showed diffuse infiltration of the subarachnoid space over all aspects of both hemispheres by the tumour. No tumour mass was identified in either brain stem or cerebellum. The aqueduct and fourth ventricle were minimally dilated and the walls of all the ventricles were finely granular.

The spinal dura was normal. The subarachnoid space was diffusely infiltrated by nodules of firm gelatinous tumour at all levels including the cauda equina.

\section{MICROSCOPICAL EXAMINATION}

There was widespread infiltration of the subarachnoid space by the tumour. This was composed of fusiform and polyhedral cells with a pale finely stippled nucleus and a rather irregularly outlined cytoplasm that stained strongly for glial fibrillary acidic protein. Nuclear pleomorphism was striking. There was some necrosis and vascular endothelial proliferation and mitotic figures were readily found. Particularly in relation to the blood vessels tumour cells tended to be enmeshed in 


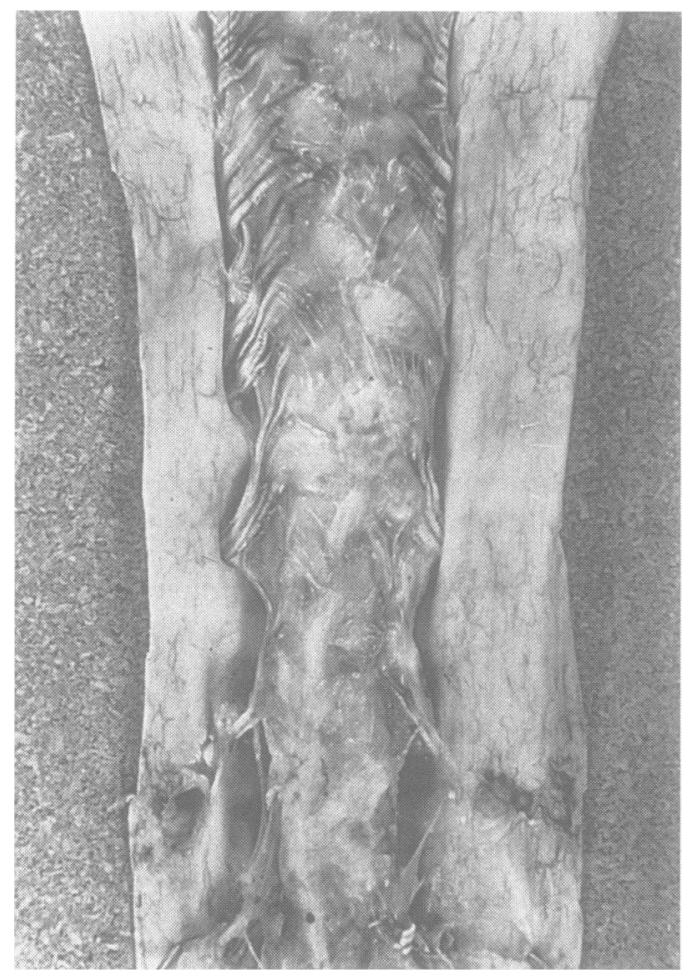

Figure 1 Nodular and diffuse tumor in subarachnoid space, dorsal aspect of spinal cord.

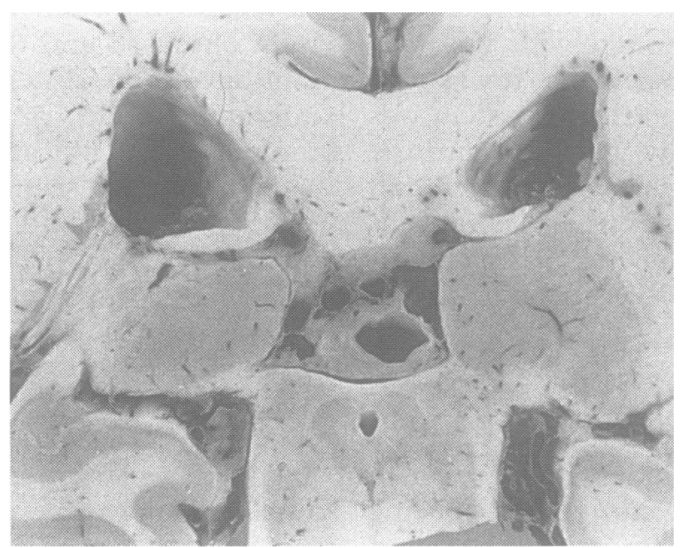

Figure 2 Coronal slice of brain at level of pineal gland with infiltration of choroidal fissure and tela choroidea by tumour.

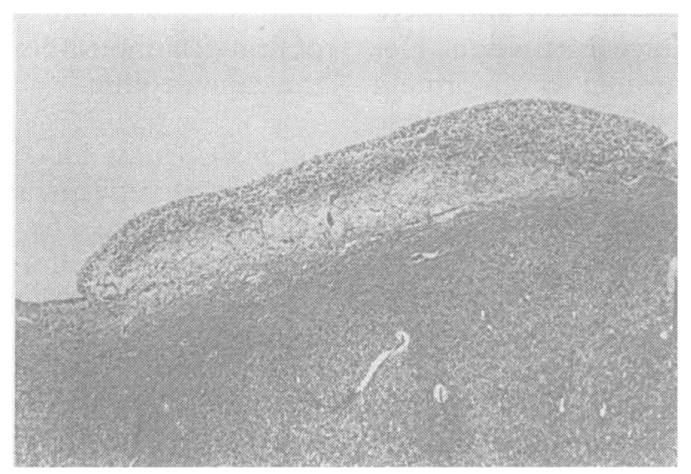

Figure 3 Ependymal ("granule" of tumour overlying mass in periventricular white matter. Haematoxylineosin, $\times 250$, reduced to $40 \%$ in reproduction.

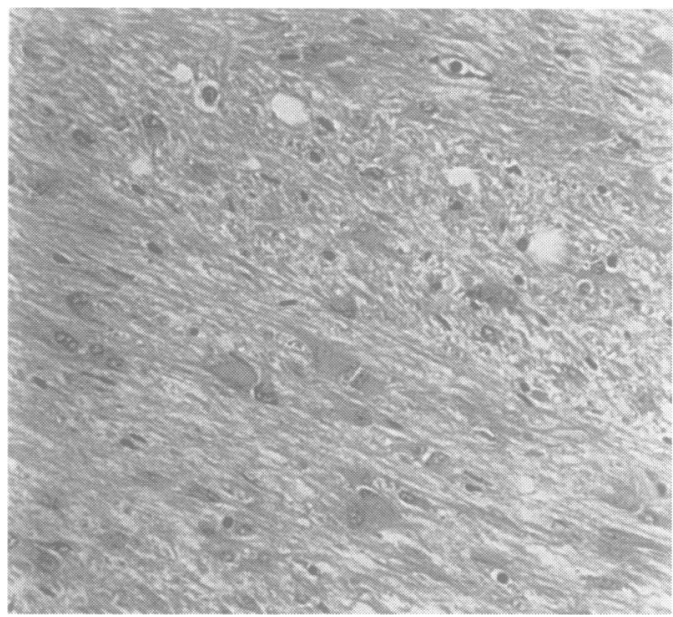

Figure 4 Periventricular astrocytoma. Haematoxylineosin $\times 250$, reduced to $65 \%$ in reproduction.

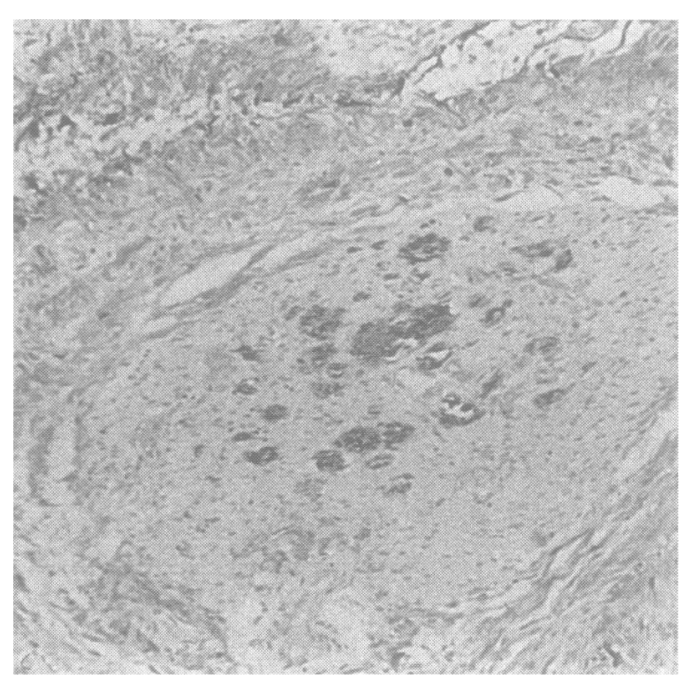

Figure 5 Astrocytoma in spinal subarachnoid space infiltrating nerve root. Stained for glial fibrillary acidic protein, $\times 100$, reduced to $51 \%$ in reproduction.

both reticulin and collagen. There was a sparse infiltrate of lymphocytes throughout.

In most areas the tumour did not transgress the pia. The one point at which this did occur was in the cervical cord where a wedge of tumour extended into the cord from the subarachnoid space. Re-examination of the brain slices still showed no overt tumour but an extensive set of blocks was taken to confirm the presence of tumour seedlings in the ventricular lining. In several of these blocks, in relation to the upper angle of the right lateral ventricle, there was a rather sparsely cellular, well differentiated astrocytoma about $2.5 \mathrm{~cm}$ in diameter that shaded off imperceptibly into the adjacent white matter (figs 1-5).

\section{Discussion}

CLINICAL DIAGNOSIS

The symptoms of diffuse involvement of the subarachnoid space by glioma or metastatic carcinoma usually lead to an initial diagnosis of an infective process such as subacute leptomeningitis or encephalitis, as in this 
instance. Examination of the CSF is helpful in differentiation. Xanthochromic fluid with a high protein content is classically associated with obstruction of the spinal canal (Froin's syndrome). In patients with subarachnoid haemorrhage the protein content depends on the amount of blood that has entered the subarachnoid space and is usually below $3.0 \mathrm{~g} / \mathrm{l}$. In the absence of spinal block, fluid with a high protein level, xanthochromia, and a low cell count is highly suggestive of a tumour process within the subarachnoid space or ventricular system. The possibility of tumour cells being regarded as lymphocytes in CSF may be clarified by the use of immunological methods that were not available when this case was investigated.

\section{LEPTOMENINGEAL GLIOMATOSIS}

The metastasis of gliomas to the subarachnoid space, whether focal or diffuse, or a combination of these, has been well recognised although uncommon since Russell and Cairns described the occurrence in a case of "benign" thalamic glioma. ${ }^{1-10}$ The primary tumour may be overt or so small or diffuse as to render its identification difficult.

The tumour reported here seems to originate in the wall of the right lateral ventricle and whereas the primary tumour is a "benign" astrocytoma the diffuse arachnoid tumour is considerably more malignant histologically; these could be graded as Kernohan I and IV respectively but the propriety of applying any such numerical system to a tumour showing such unusual behaviour is problematic. Gliomas do, notoriously, show great variation in their histology but it is interesting that that seen here is so geographically precise and leads, inevitably, to the speculation that some factor in the CSF environment has enhanced its activity.

Primary gliomas presenting as a focal mass in the cranial and spinal leptomeninges are amply validated ${ }^{10-15}$ but rare and presumably arise from heterotopic glia.

We must, however, share the profound reservations of Russell and Rubinstein ${ }^{16}$ regarding the concept of primary lepto- meningeal gliomatosis; this being the label attached to a condition in which the leptomeninges are diffusely infiltrated by a glioma, usually of the astrocytic series in the apparent absence of an intraneural mass. ${ }^{1016-21}$ It is not always clear just how exhaustively the brain and spinal cord have been examined histologically and the difficulty experienced with the present case greatly reinforces the need for continued scepticism.

1 Russell DS, Cairns H. Spinal metastases in a case of cerebral glioma of the type known as astrocytoma fibrillare. F Pathol 1930;33:383-9

2 Cairns H, Russell DS. Intracranial and spinal metastases in gliomas of the brain. Brain 1931;54:377-420

3 Ehrlich SS, Davies RL. Spinal subarachnoid metastases from primary intracranial glioblastomas. Cancer 1978; 42:2854-64

4 Eade OE, Urich H. Metastatic glioma in young subjects. f Pathol 1971;103:245-56.

5 Polmeteer FE, Kernohan JW. Meningeal gliomatosis. A study of 42 cases. Arch Neurol Psychiatry 1947;57: 593-616.

6 Yung WA, Horten BC, Shapiro WR. Meningeal gliomatosis: a review of 12 cases. Ann Neurol 1980;8:605-8.

7 Simonati A, Mazza C, Rizzuto N. An unusual case of meningeal gliomatosis. Acta Neuropathol (Berl) 1981; (suppl VIII):97-100.

8 McLaughlin JE. Juvenile astrocytoma with subarachnoid spread. F Pathol 1976;118:101-7.

9 Bhrany D, Murphy MC, Horenstein S, Silbert SW. Diffuse periventricular and meningeal glioma. Acta Neuropathol (Berl) 1973;30:343-9.

10 Whelan HT, Sung JH, Mastri AR. Diffuse leptomeningeal gliomatosis; report of three cases. Clin Neuropathol 1987; 6:164-8.

11 Bailey OT. Relation of glioma of the leptomeninges to neuroglioma rests; report of a case of astrocytom a f the meninges. Arch Pathol 1936;31:358-600.

12 Best PV. Intracranial gliomatosis. $f$ Neurol Neurosurg Psychiatry 1963;26:249-56.

13 Cooper IS, Craig WM, Kernohan JW. Tumour of the spinal cord; primary extramedullary gliomas. Surg Spinal cord; primary extram

14 Horoupian DS, Lax F, Suzuki K. Extracerebral leptomeningeal astrocytoma mimicking a meningioma. Arch Pathol Lab Med 1979;103:676-9.

15 Shuangshoti S, Kasantikul V, Suwanwela N, Suwanwela C. Solitary primary intracranial extracerebral glioma. $\mathcal{f}$ Neurosurg 1984;61:771-81.

16 Russell DS, Rubinstein LJ. Pathology of tumours of the nervous system. 5th ed. London: Arnold, 1988:716-7.

17 Ho K, Hoschner JA, Wolfe DE. Primary leptomeningeal gliomatosis. Symptoms suggestive of meningitis. Arch Neurol 1981;38:662-6.

18 Kitihara M, Katakura R, Nada T, Namiki T, Suzuki J. Diffuse form of primary leptomeningeal gliomatosis. f Neurosurg 1985;63:283-7.

19 Korein J, Feigin I, Shapiro MF. Oligodendrogliomatosis with intracranial hypertension. Neurology 1957;7:

20 Sumi SM, Leffman H. Primary intracranial leptomeningeal glioma with persistent hypoglycorrhachia. 7 Neurol Neurosurg Psychiatry 1968;31:190-4.

21 Bailey P, Robitaille Y. Primary diffuse leptomeningeal gliomatosis. Can $\mathcal{F}$ Neurol Sci 1985;12:278-81. 